\title{
A Study on the Use of Information by Chiropractors
}

by

Penelope Jane Dawson B.Sc

Submitted to the Department of Library and Information Studies, Victoria University of Wellington in partial fulfilment of the requirements for the degree of Master of Library and Information Studies 
The author would like to thank Alastair Smith, Dr. Noel Dawson, Dr. Jim Stinear and Dr. Bernadette Murphy (from the New Zealand Chiropractic Association Centre for Chiropractic Ltd) for their support, advice and comments regarding this study. 


\section{Table of Contents}

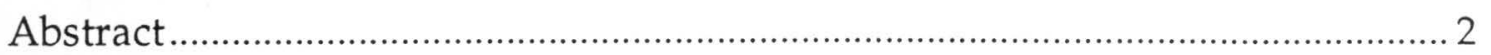

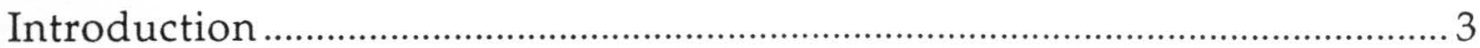

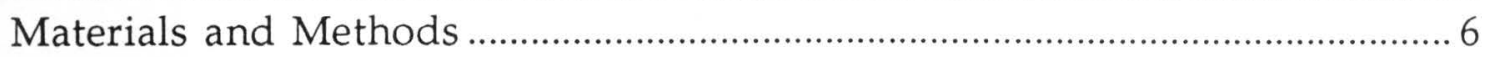

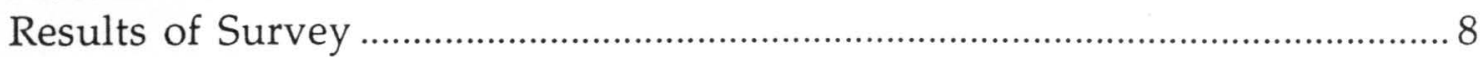

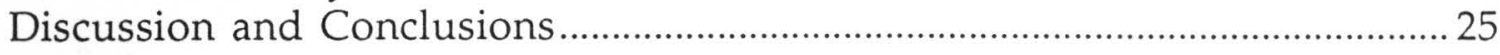

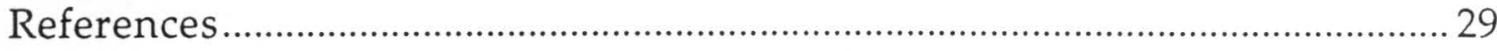




\section{Abstract}

A study of the use of information by chiropractors in New Zealand was undertaken in order to produce guidelines for the establishment of library services to practitioners, and to fill a gap in the body of user studies knowledge.

This study used a survey to collect data which was then analysed using descriptive statistics.

It was found that:

1. The library will need to market its services strongly to the practitioners

2. Chiropractors are different to orthodox medical practitioners in that they use monographs more than journals and colleagues, but are similar to medical physicians because they rarely use libraries and prefer using their own personal collection.

3. Electronic information use is low in spite of high computer use and will therefore need special marketing and training to create awareness and use.

4. There does not seem to be a need for special recent graduate services as there is no significant linear relationship between professional age and print information use

5. Rural chiropractors and urban chiropractors do not use electronic information any differently, so will probably not need special training or services in this area. They can be accommodated into services as a group. 


\section{Introduction}

The New Zealand Chiropractic Association Centre for Chiropractic Ltd. (NZCACC) have recently set aside money to establish the NZCA Centennial Library. This study is undertaken by the librarian in order to gain some insight into the information use habits of chiropractors so guidelines for library services can be established.

The NZCACC established a School for Chiropractic in 1994. It is the only school of chiropractic in New Zealand. This year there is are 88 students enrolled in the 5 year course.

The NZCACC School for Chiropractic students and their teaching staff, as well as practitioners of chiropractic who belong to the NZCA are the potential users of the NZCA Centennial Library (NZCACL). The youth of the school created a unique and critical time in which to do a study of information use.

Use studies are a common phenomenon in the world of librarianship (Matyn 1974; Bouazza 1988) but few have been useful (Matyn 1974), and none have studied the use of information by chiropractors who are unique discipline that combine art, science and philosophy.

Several themes relevant to this study have emerged from the studies scientific information use.

Firstly, researchers rely on journal information more than applied technologists who tend to use oral communication as their main information source (Wood 1971).

Secondly, the information channel used the most is not always the one that gives the highest quality information, but is the one that is the most accessible to the individual (Wood 1971).

Lastly, the use of formal communication sources is higher for younger scientists and medical practitioners who have not yet developed an "invisible college" (Lin and Garvey 1972; Strasser 1978; Verhoven, Boerma et al. 1995). If a similar trend occurs in this study, special services to professionally young chiropractors may need to be set up.

Information use studies dealing with health professionals indicate that practising physicians made little use of libraries because they had no time to search for information beyond what they could obtain from their colleagues who were used as the information source the most frequently (Strasser 1978; Stinson and Mueller 1980; Verhoven, Boerma et al. 1995). If the use 
of libraries by chiropractors is the same as the results of these studies indicate, there will need to be marketing procedures implemented by the NZCA Centennial Library.

When medical practitioners did use the library, their requests through interlibrary loan and their use of material in the libraries show that periodical information is used the highest (Gomes 1970; Strasser 1978; Lovas, Graham et al. 1991). The main use of this material was for clinical information (Lovas, Graham et al. 1991). Chiropractors could have the same habits.

A study by Strasser (1978) found that radiologists were avid information seekers. They used information sources ${ }^{1}$ more frequently than other respondents in the study ${ }^{2}$ (Strasser 1978). If chiropractors use radiological information regularly, they may also demonstrate such a trend.

Unsolicited material was used extensively in the study of health professionals by Stinson and Mueller (1980), particularly by those in rural, solo practise. It may be that chiropractors show a similar inclination.

A study of veterinarian information use showed a reasonably high use (35\%) of computers to get bibliographic information (Pelzer and Leysen 1991). In another study (Verhoven, Boerma et al. 1995), rural medical practitioners were found to perform fewer on-line searches than those in urban practise. The frequency of use of computers and electronic information sources by chiropractors is unknown so this study investigates this aspect of information use too.

Students in problem-based learning programs use the library extensively (Marshall, Fitzgerald et al. 1993). The NZCACC School for Chiropractic follow a case-based learning program similar to problem-based learning. Library services will need to be tailored to their expected high use, so a study of chiropractors information use habits could give the librarian some insight into two of the main user groups of the NZCA Centennial Library.

Objective: To discover how chiropractors use information.

\section{Aims:}

- To establish the use patterns exhibited by chiropractors of information sources such as journals, monographs, colleagues and electronic material

- To find out the frequency of use of various information sources

${ }^{1}$ Journal papers, colleagues, books, seminars and such like, personal libraries, abstracting and indexing services, audiovisual material, exhibitions, reference material, sales representatives, computerised information services, correspondence courses

${ }^{2}$ Family practitioners, internists, paediatric, general surgeons, ob./gyn., anaesthesiologists 
- To see where New Zealand chiropractors get their information from at present

- To find out the state of computer use among chiropractors

- To produce guidelines for the NZCACC librarian on the nature of library services for students and practitioners

\section{Hypotheses:}

1. Chiropractors do not use information any differently from physicians in orthodox medical practice. That is:

- they rarely use libraries (Strasser 1978)

- frequently use colleagues, and journals, and unsolicited literature (Gomes 1970; Wood 1971; Strasser 1978; Stinson and Mueller 1980; Pelzer and Leysen 1991; Verhoeven, Boerma et al. 1995)

- less frequently use monographs, and electronic information (Gomes 1970; Wood 1971; Strasser 1978; Stinson and Mueller 1980; Pelzer and Leysen 1991; Bird and Heekin 1994; Verhoeven, Boerma et al. 1995)

2. Chiropractors get their information from their own collection or the collection of others, and from their colleagues, rather than from the library or an electronic source

3. Professionally young practitioners will use the printed resources more than colleagues (Strasser 1978; Verhoeven, Boerma et al. 1995)

4. Rural chiropractors do not use electronic information any more than urban chiropractors (Verhoeven, Boerma et al. 1995)

\section{Assumptions}

- That chiropractors use information enough for the study to be significant

- That chiropractic students who follow a CBL program use information in a similar manner to practitioners

- That chiropractors have personal collections they can draw upon

- That chiropractors have a network of colleagues to draw information from 


\section{Materials and Methods}

The tool used to gather the results was a survey sent to all chiropractors belonging to the NZCA. This happens to be the majority of chiropractors in New Zealand.

A pre-test was sent to all Auckland chiropractors in the NZCA (22 in total). All surveys to these chiropractors were returned. A copy of the pre-test survey is enclosed in Appendix A.

Following the pre-test and comments by my supervisor, the survey was revised and sent to NZCA members around the country (90 in total). A copy of the revised survey is enclosed in Appendix B.

One hundred and ten surveys were sent in total.

Follow-up of non-returnees was not possible owing to the time limits of the project.

Respondents of the second wave of surveys were given until the 9th of February to return their survey. Any that arrived after this date were ignored.

The results of the questions were treated by tallying the frequency of responses and graphing these frequencies to show trends clearly ${ }^{3}$.

${ }^{3} \mathrm{Graphs}$ were generated using the Macintosh program DeltaGraph ${ }^{\mathrm{TM}} 1.5$. 
Results were also evaluated using simple descriptive statistics ${ }^{4}$. The frequency categories were given a value from $0-5$ in order to do these statistics ${ }^{5}$. The following key will make this clear.

Not at all $=0$

1-6 times a year $=1$

Once a month $=2$

Once a fortnight $=3$

Once a week $=4$

More than once a week $=5$

${ }^{4}$ The Macintosh program StatView $512+^{\mathrm{TM}}$ was used to generate statistical data, including regression graphs. ${ }^{5}$ So when an average of 2.7 is referred to the interpretation is: the average frequency of use is between once a month and once a fortnight 


\section{Results of Survey}

The response rate for the survey was $54 \%$.

Fig. 1. Frequency distribution of the professional age of chiropractors

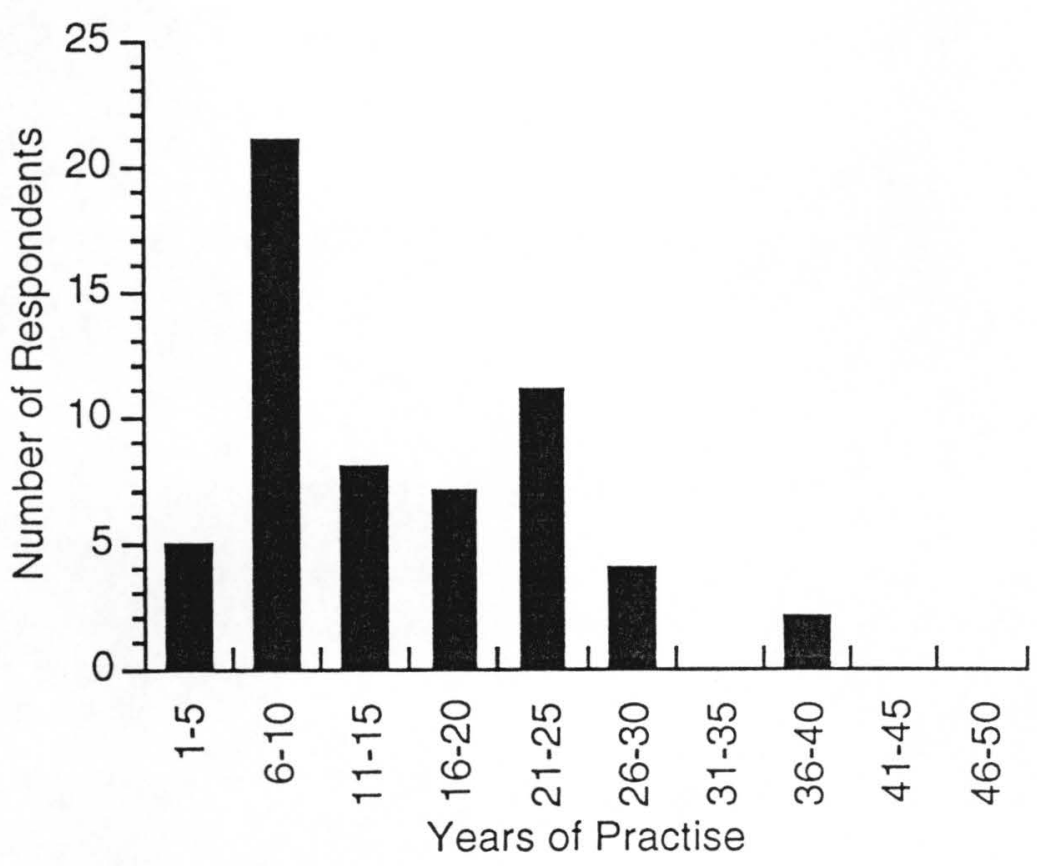

The frequency of older practitioners (26 years of practise or more) in the sample is low; the number of younger practitioners higher. 
Fig. 2. Number of chiropractors in each type of practise

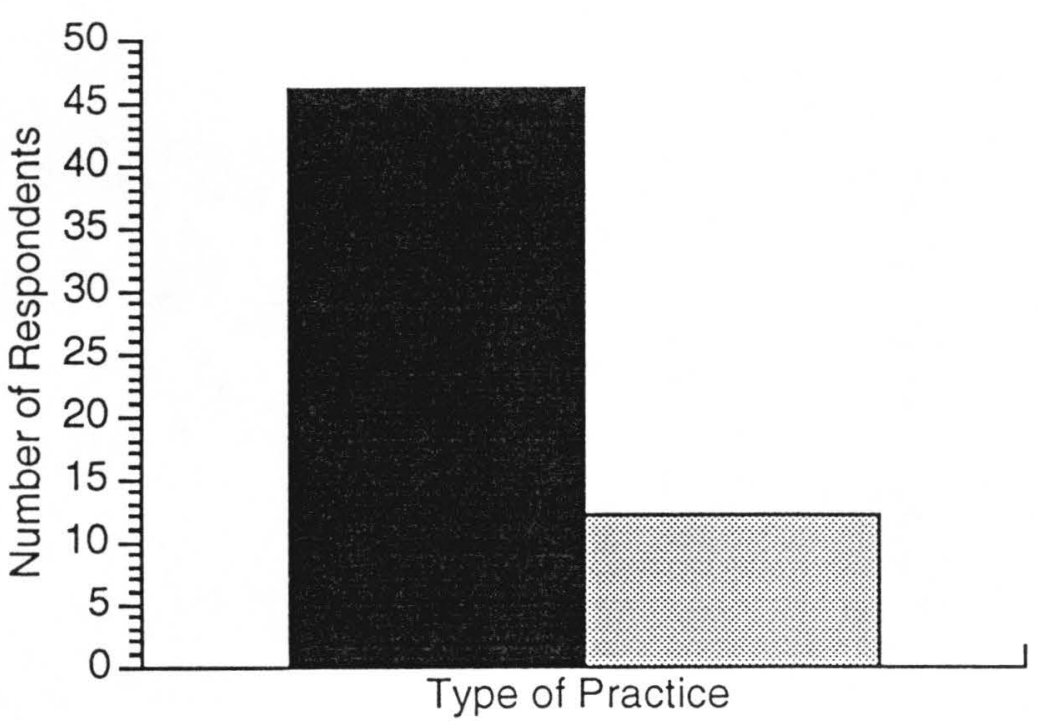

\section{City and Suburbs \\ Predominantly Rural}

Most chiropractors in the sample have practices in cities or their suburbs. Only $20.7 \%$ have practises in predominantly rural areas.

Fig. 3. Number of chiropractors using radiological information

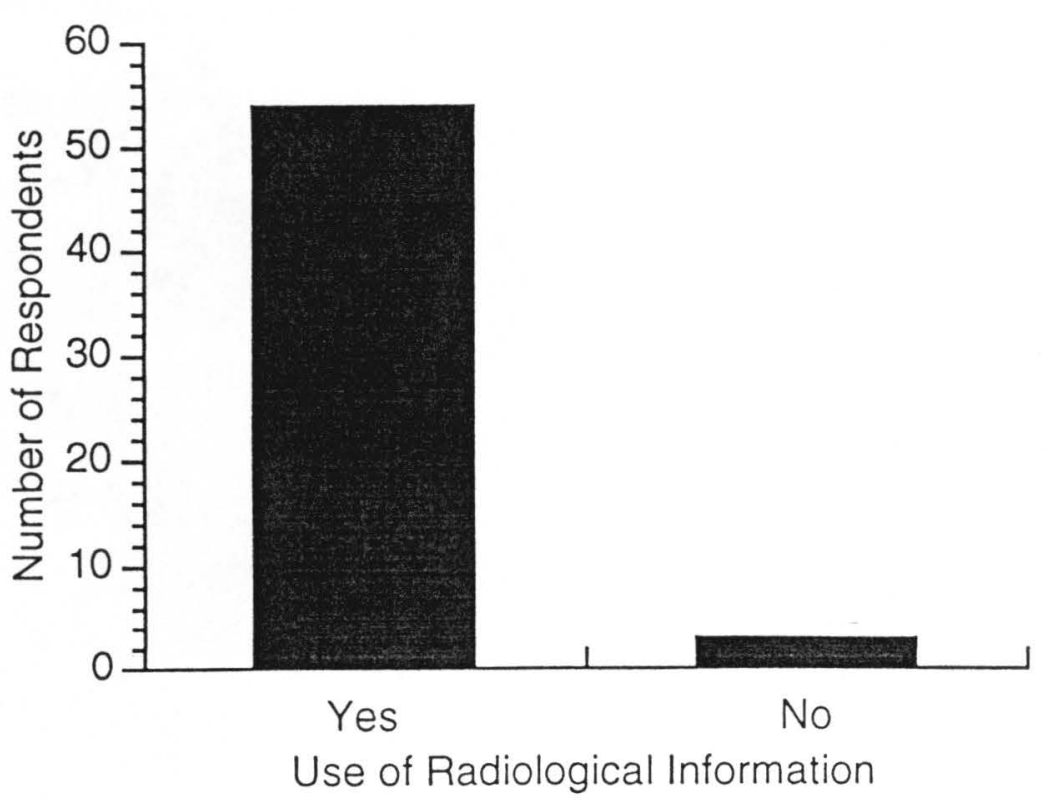

Almost all chiropractors use radiological information in their practice; $5.2 \%$ say they do not use this type of information. 
Fig. 4. Number of chiropractors using computer technology

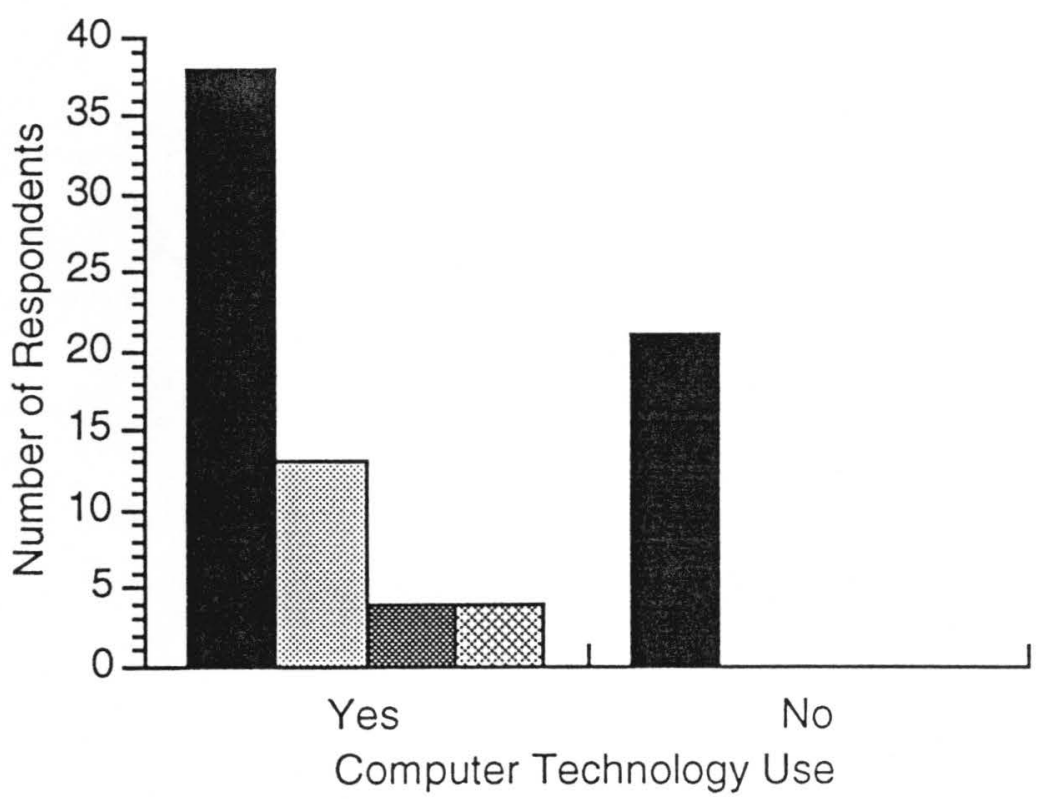

\begin{tabular}{|c|c|}
\hline & Computer \\
\hline 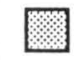 & Modem \\
\hline & E-Mail \\
\hline 図 & Internet \\
\hline
\end{tabular}

A high (64.4) percentage of respondents have access to computers they use regularly; $34.2 \%$ of these have a modem, and 10.5\% have e-mail and/or access to the Internet. A significant number $(35.6 \%)$ of practitioners do not use, or do not have access to a computer. 
Fig. 5. Frequency distribution of the use of different types of information

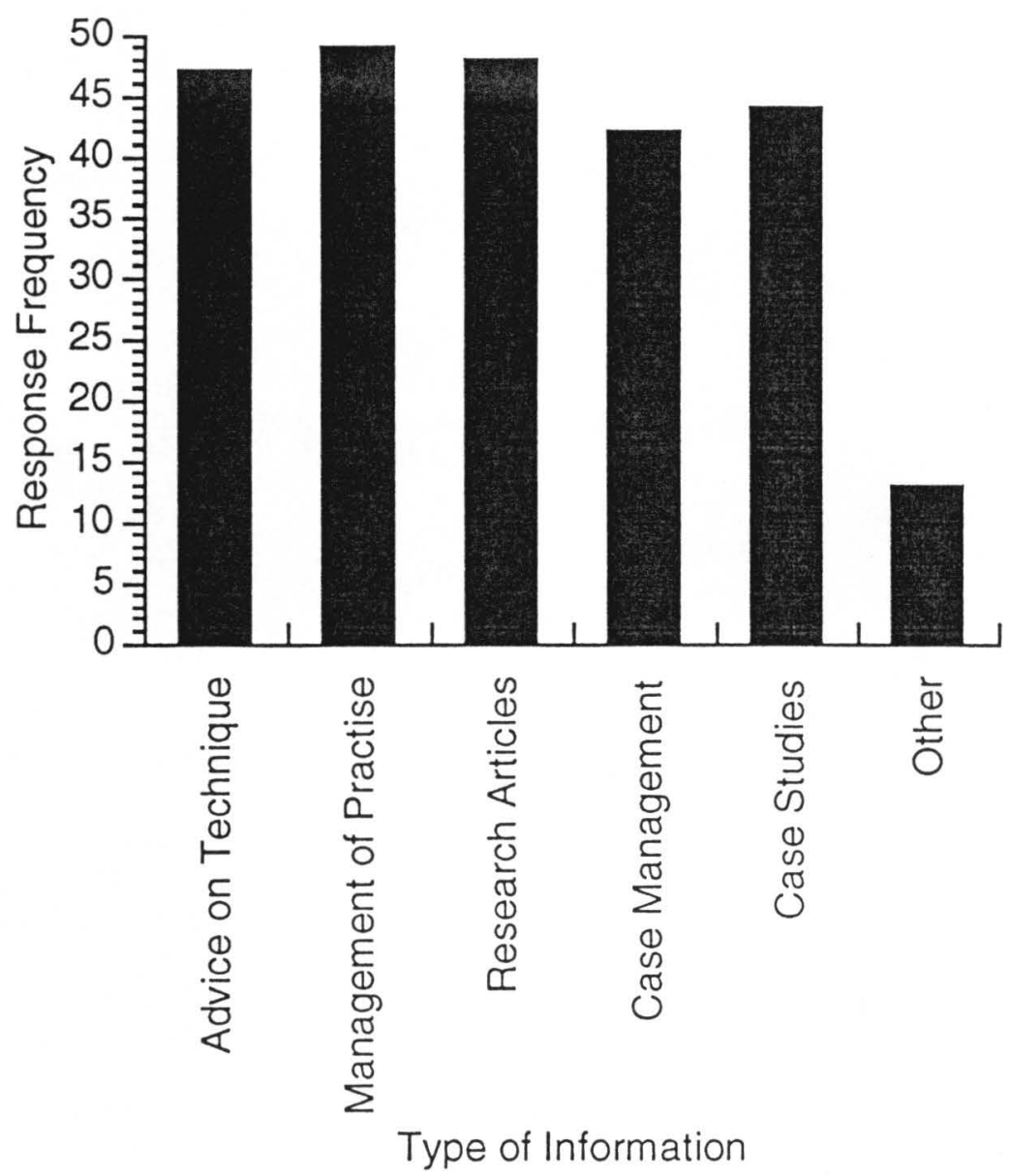

Chiropractors who responded to the survey find the above types of information more or less equally useful. 
Fig. 6. Frequency distribution of the use of different information sources

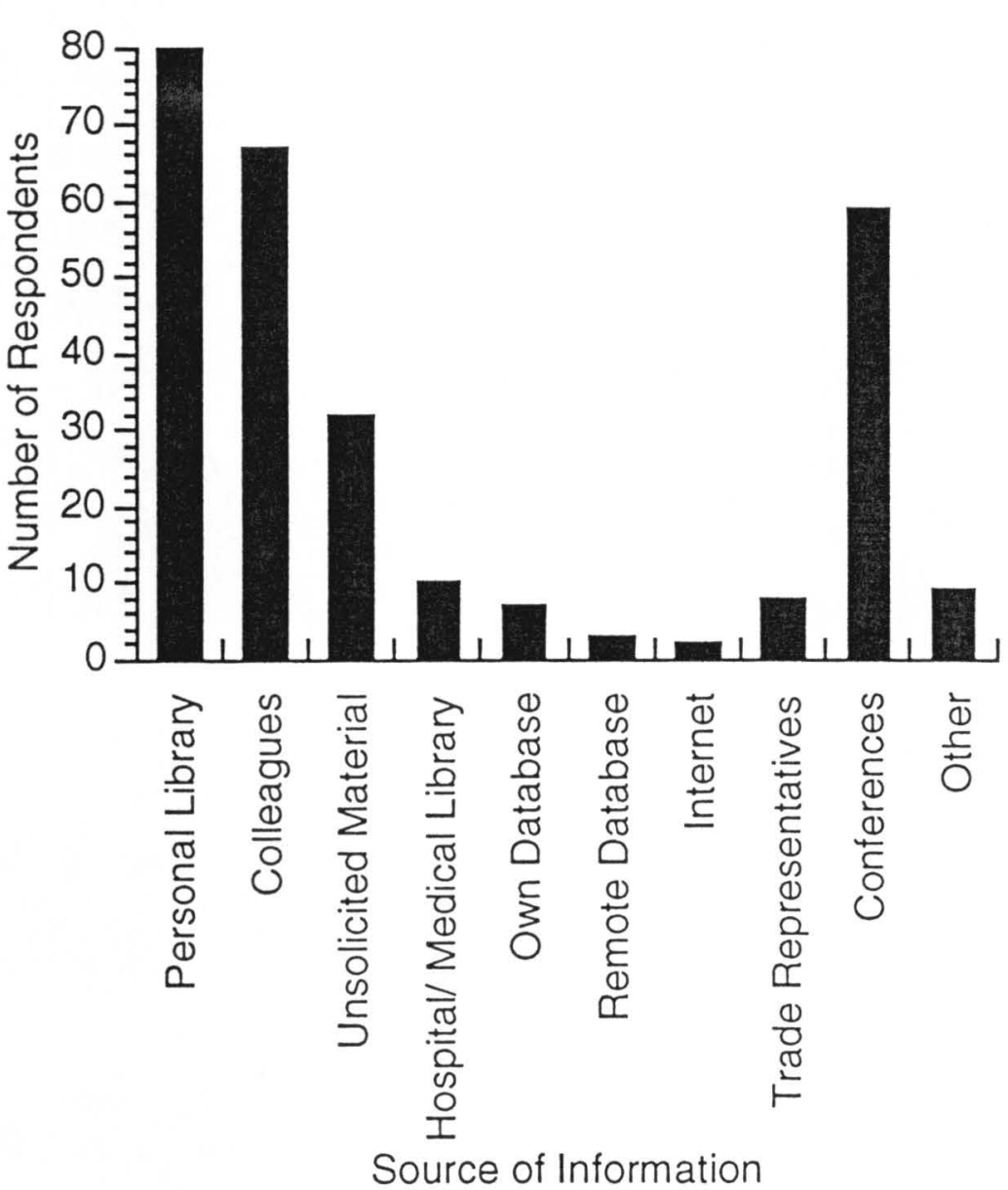

The most frequent information source used by the survey respondents was their personal library $(72 \%)$. Other frequently used sources were their colleagues $(61.8 \%)$ and conferences (54.5\%). Unsolicited material was used to a lesser degree (29\%). 
Fig. 7. Frequency of library use

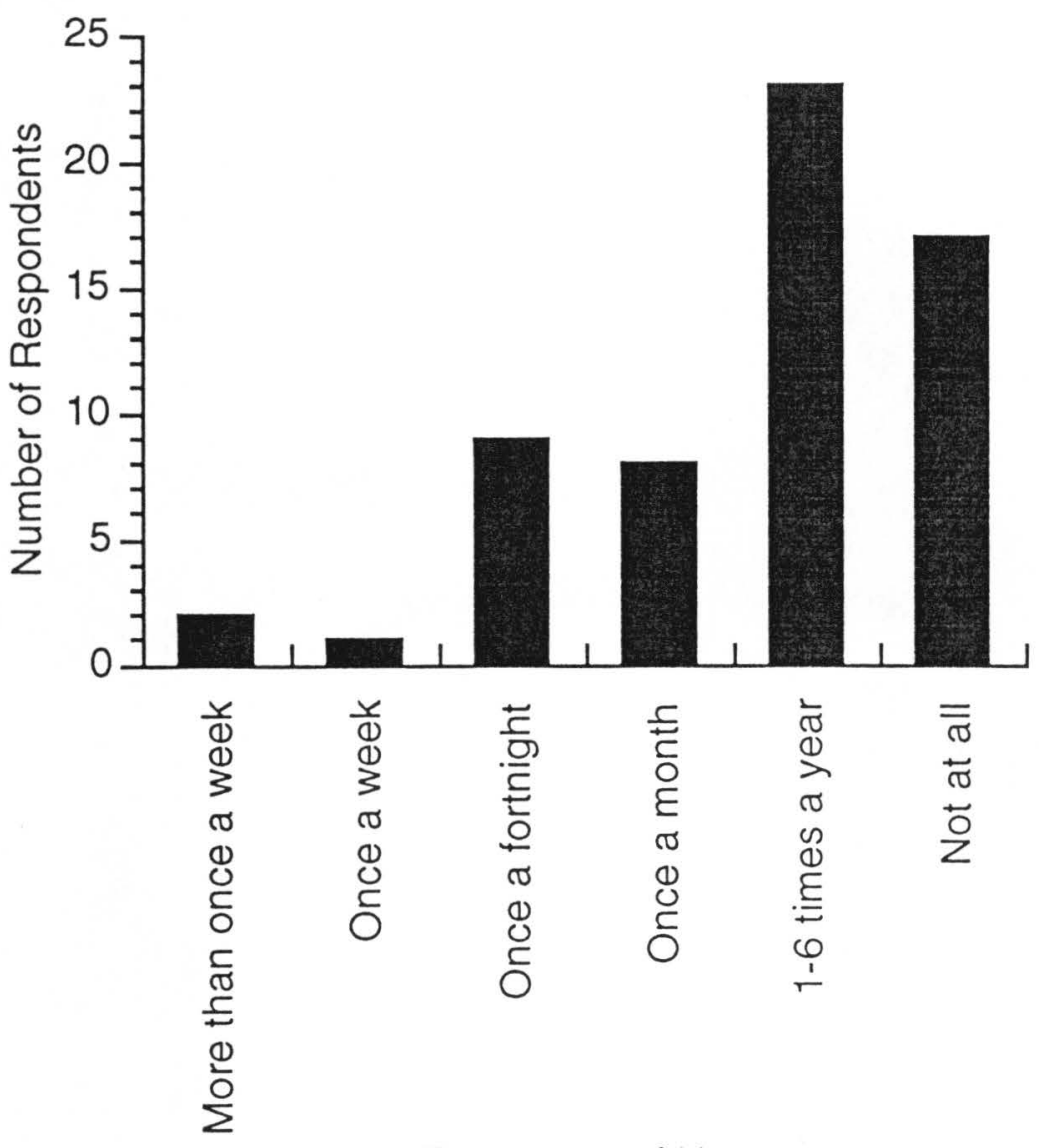

Frequency of Use

\begin{tabular}{|l|l|l|l|}
\hline Mean & Standard Dev. & Median & Mode \\
\hline 1.36 & 1.28 & 1 & 1 \\
\hline
\end{tabular}

Chiropractors in the survey do not use libraries very often to help in their practise; the average frequency of use is 1-6 times a year. 
Fig. 8. Frequency distribution of the number of journals read each month

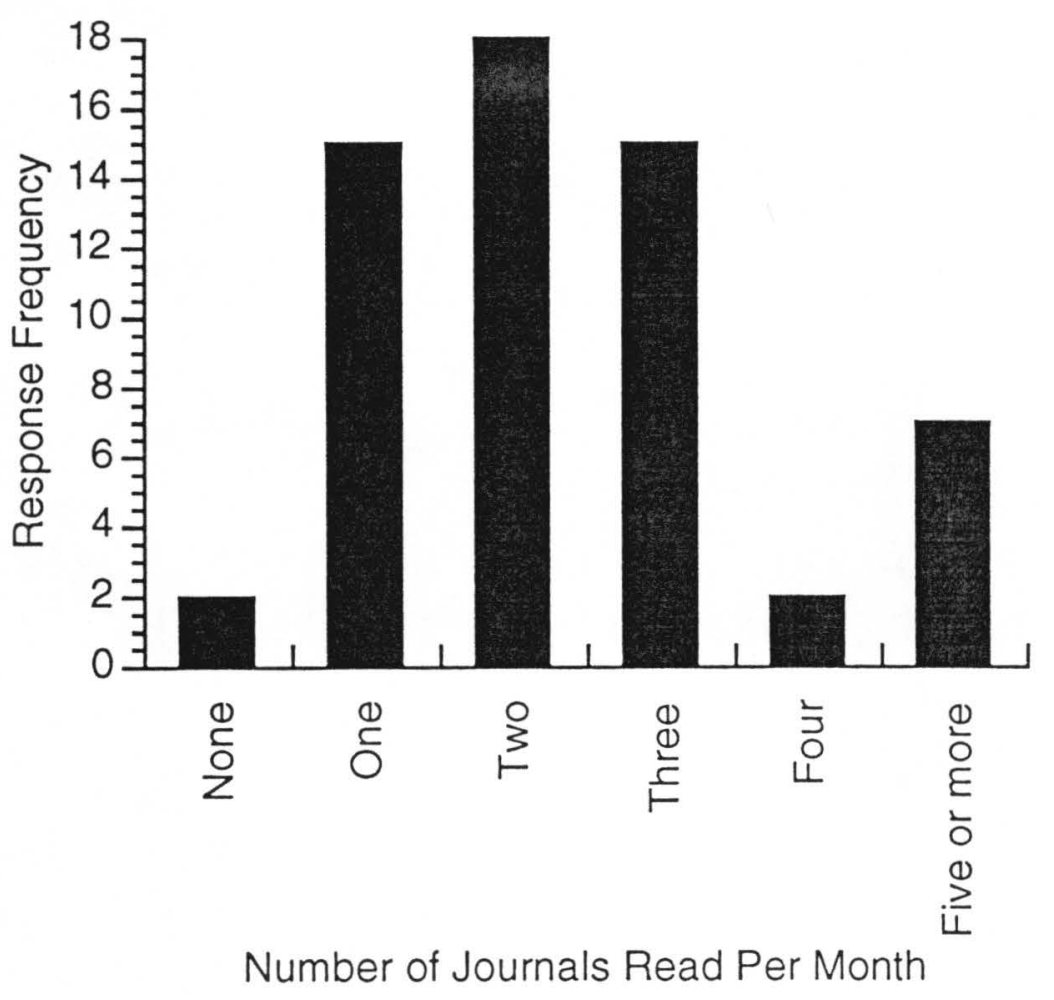

\begin{tabular}{|l|l|l|l|}
\hline Mean & Standard Dev. & Median & Mode \\
\hline 2.3 & 1.32 & 2 & 2 \\
\hline
\end{tabular}

The average number of journals read per month is between 2 and 3. The journal titles read most frequently were:

- Journal of Manipulative and Physiological Therapeutics (44\% of respondents)

- Dynamic Chiropractor (45.6\%)

- $\quad$ The Chiropractic Report (31.6\%) 
Fig. 9. Frequency of journal use by chiropractors

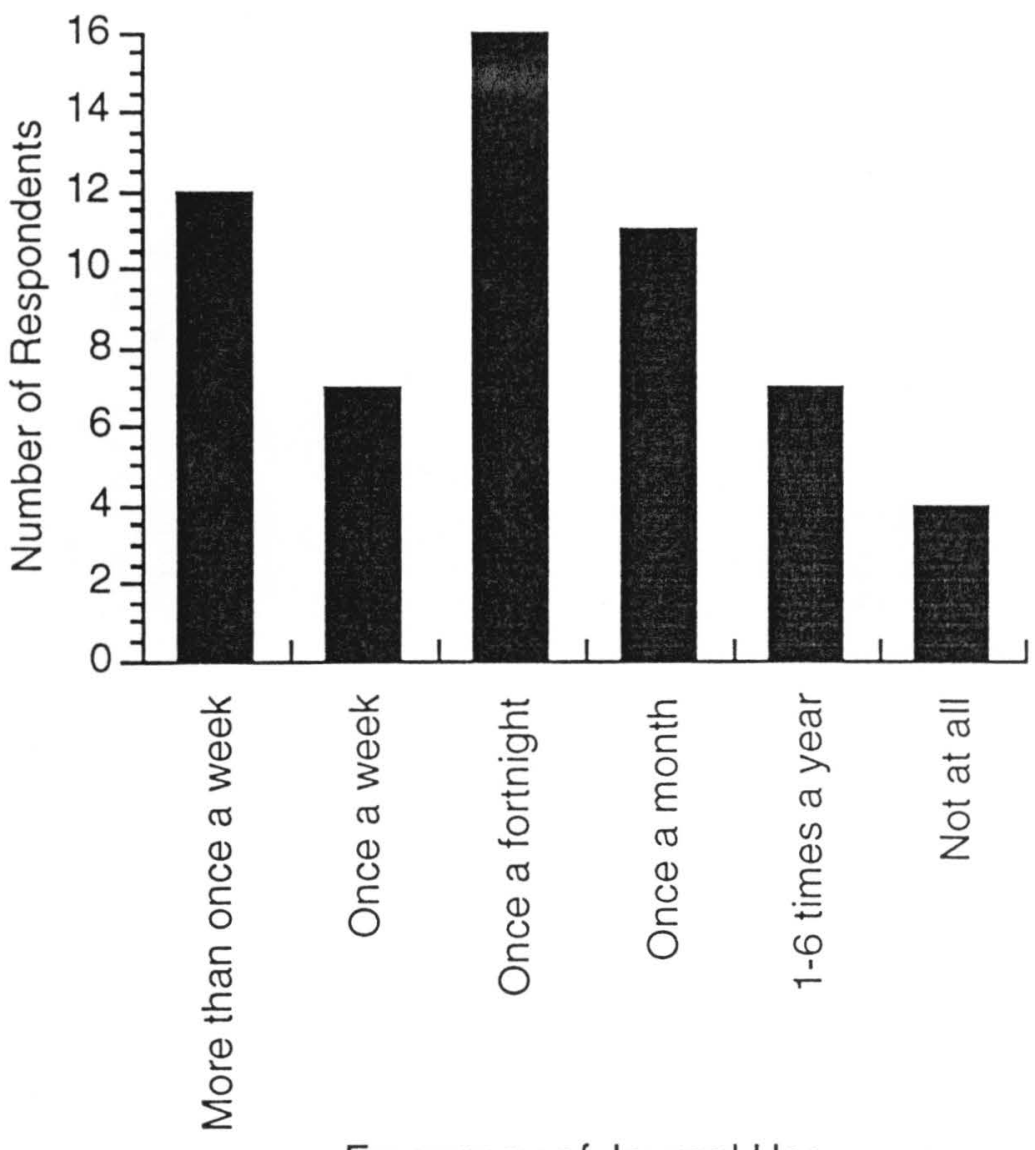

Frequency of Journal Use

\begin{tabular}{|l|l|l|l|}
\hline Mean & Standard Dev. & Median & Mode \\
\hline 2.89 & 1.52 & 3 & 3 \\
\hline
\end{tabular}

The mean frequency of journal use in practise occurs between once a month and once a fortnight. 
Fig. 10. Frequency of book use by chiropractors

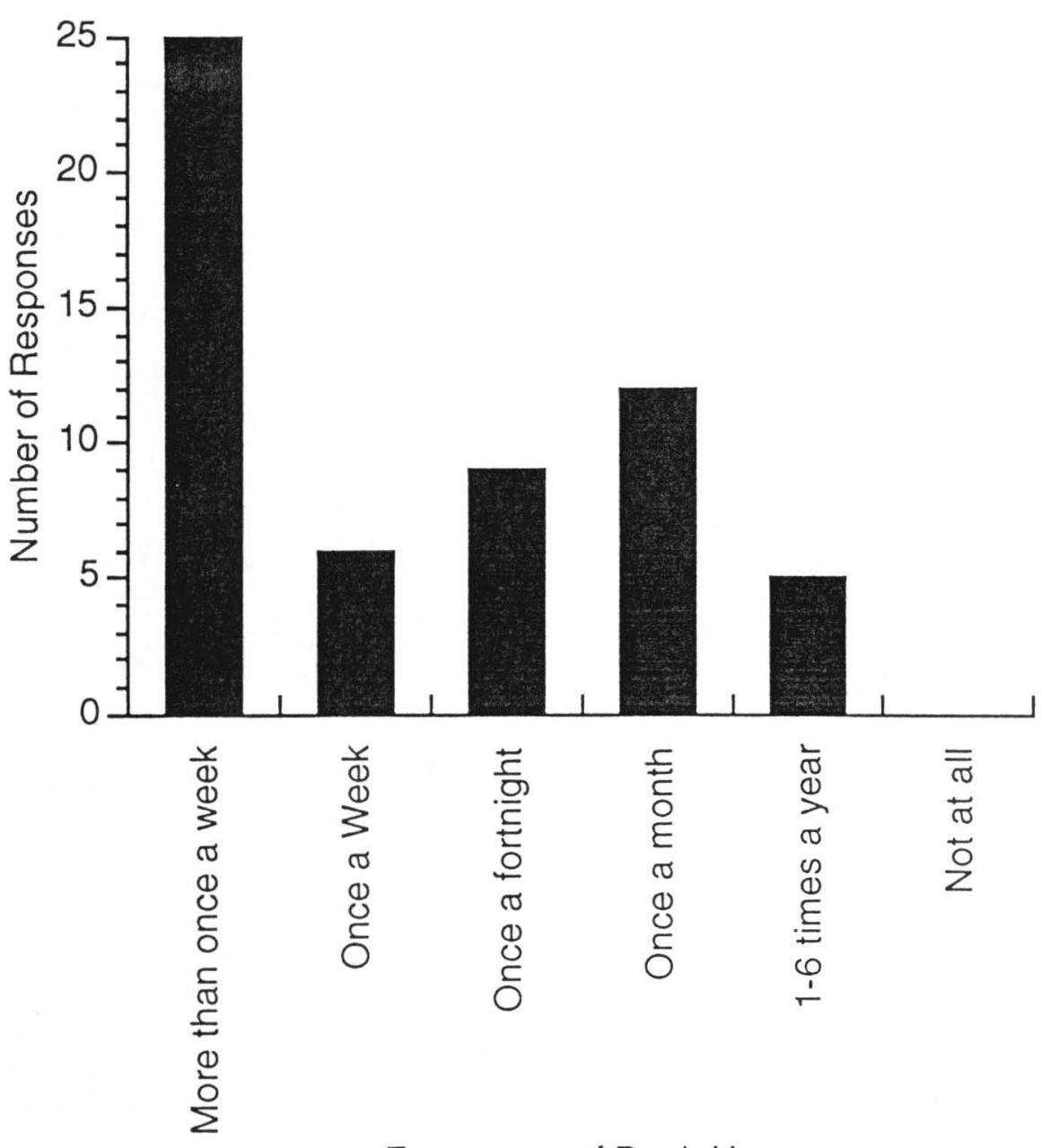

Frequency of Book Use

\begin{tabular}{|l|l|l|l|}
\hline Mean & Standard Dev. & Median & Mode \\
\hline 3.6 & 1.45 & 4 & 5 \\
\hline
\end{tabular}

Books are used more frequently than journals - between once a fortnight and once a week. The mode indicates the average to be skewed by those respondents with lower book use frequency, such that book use is probably higher than once a week. 
Fig. 11. Frequency distribution of the use of colleagues

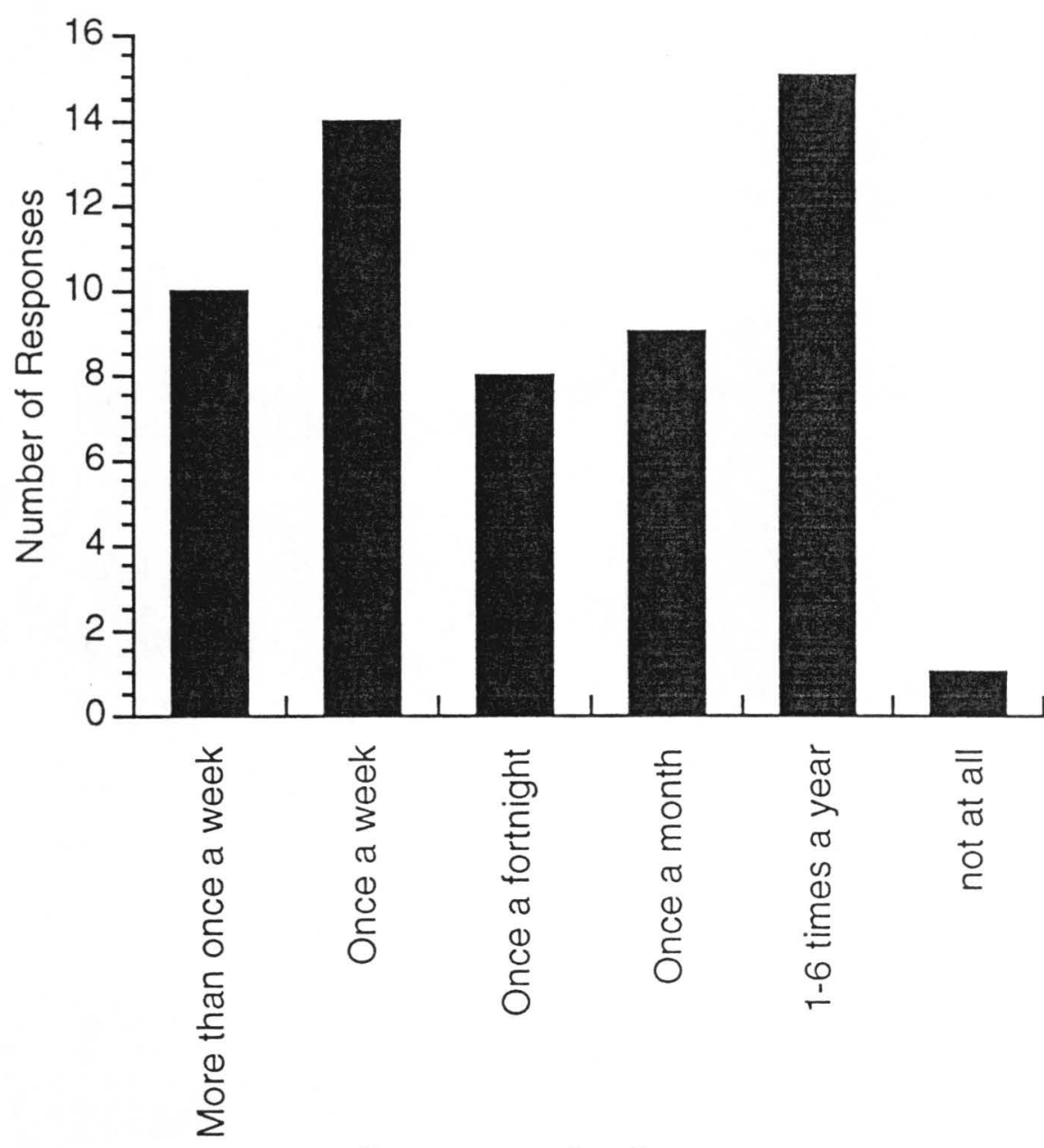

Frequency of colleague use

\begin{tabular}{|l|l|l|l|}
\hline Mean & Standard Dev. & Median & Mode \\
\hline 2.86 & 1.5 & 3 & 1 \\
\hline
\end{tabular}

Respondents turn to colleagues for information between once a month and once a fortnight the same frequency as journal use. 
Fig. 12. Frequency distribution of the use of electronic information sources

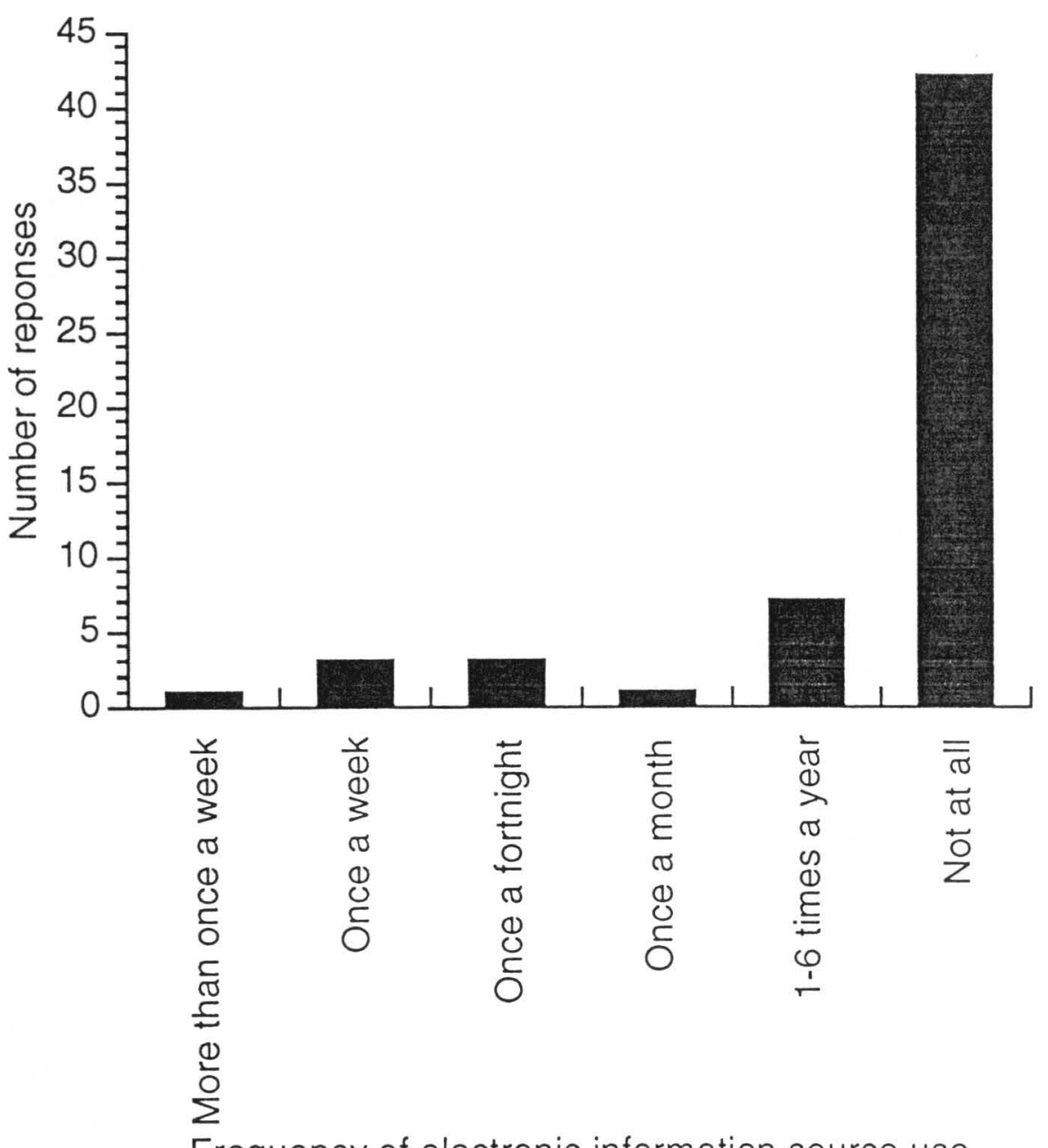

Frequency of electronic information source use

\begin{tabular}{|l|l|l|l|}
\hline Mean & Standard Dev. & Median & Mode \\
\hline 0.61 & 1.26 & 0 & 0 \\
\hline
\end{tabular}

Use of electronic resources is very low, the average being between never and 1-6 times a year. 
Fig. 13. Type of access by those chiropractors who use electronic information sources

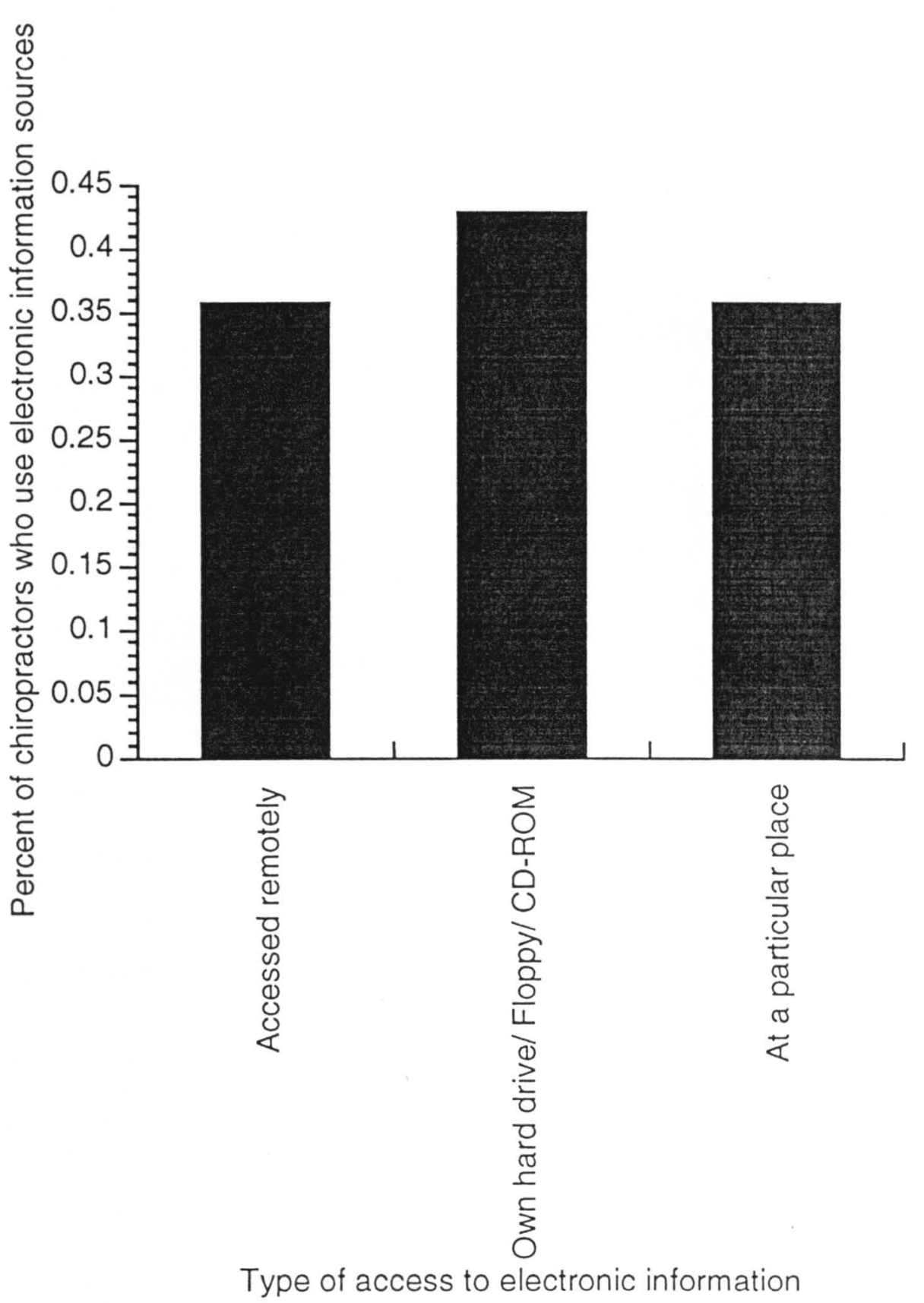

Of the few chiropractors who use electronic resources, more (43\%) have them in their possession than those who access them remotely $(36 \%)$ or go to a particular place to use them $(36 \%)$. 
Fig. 14. Perceived importance of different information sources

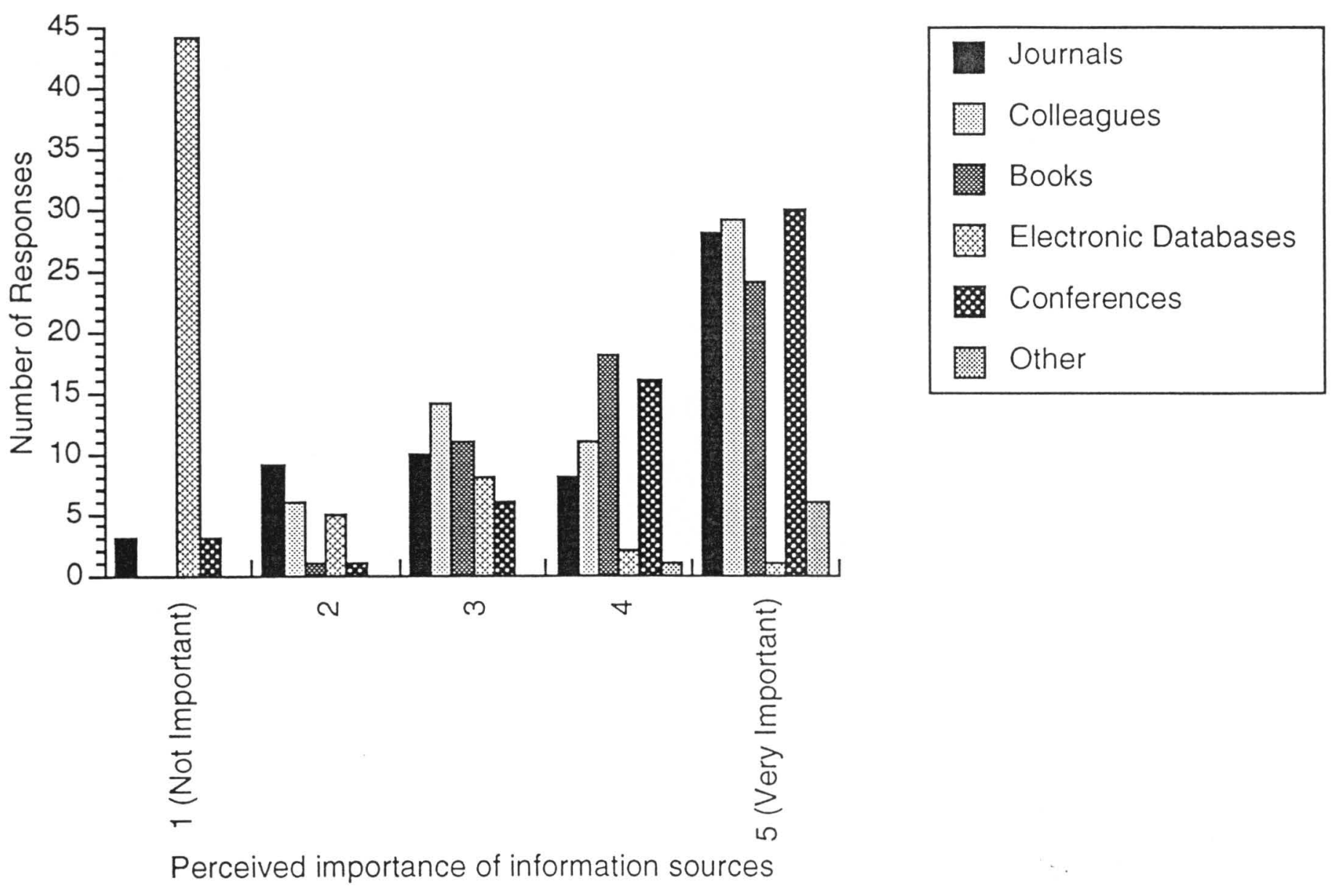

Clearly electronic databases are perceived as being unimportant by most chiropractors who responded to the survey. However, conferences, colleagues and journals were seen to be very important. Although books were said to be used the most frequently in earlier questions, fewer respondents chose the "very important" category for books than those that said conferences, colleagues and journals were very important. Instead, the perceived importance of books ranged from medium to very important. 
Fig. 15. Paired t-test of No Difference Between Frequency of Use of Electronic Resources by Rural and City/Suburban Practitioners

\section{Paired t-Test $X_{1}:$ Rural Practitioners $Y_{1}:$ City/Suburban Practitioners}

\begin{tabular}{|l|l|l|l|}
\hline DF : & Mean $X-Y:$ & Paired t ralue: & Prob. (2-tail): \\
\hline 11 & .417 & 1.101 & .2945 \\
\hline
\end{tabular}

Ho: There is no difference between the amount of electronic resource use by rural and city/suburban practitioners

H1: There is a difference between the amount of electronic resource use by rural and city/suburban practitioners.

P-value $($ at $5 \%)=1.796$

The $t$-value is not significant at the $5 \%$ level, ie. there is less than a $1 / 20$ chance that there is a difference between the amount of electronic resource use by rural and city/suburban practitioners. Therefore we fail to reject the null hypothesis.

Fig. 16. Relationship Between Professional Age and the Frequency of Journal Use

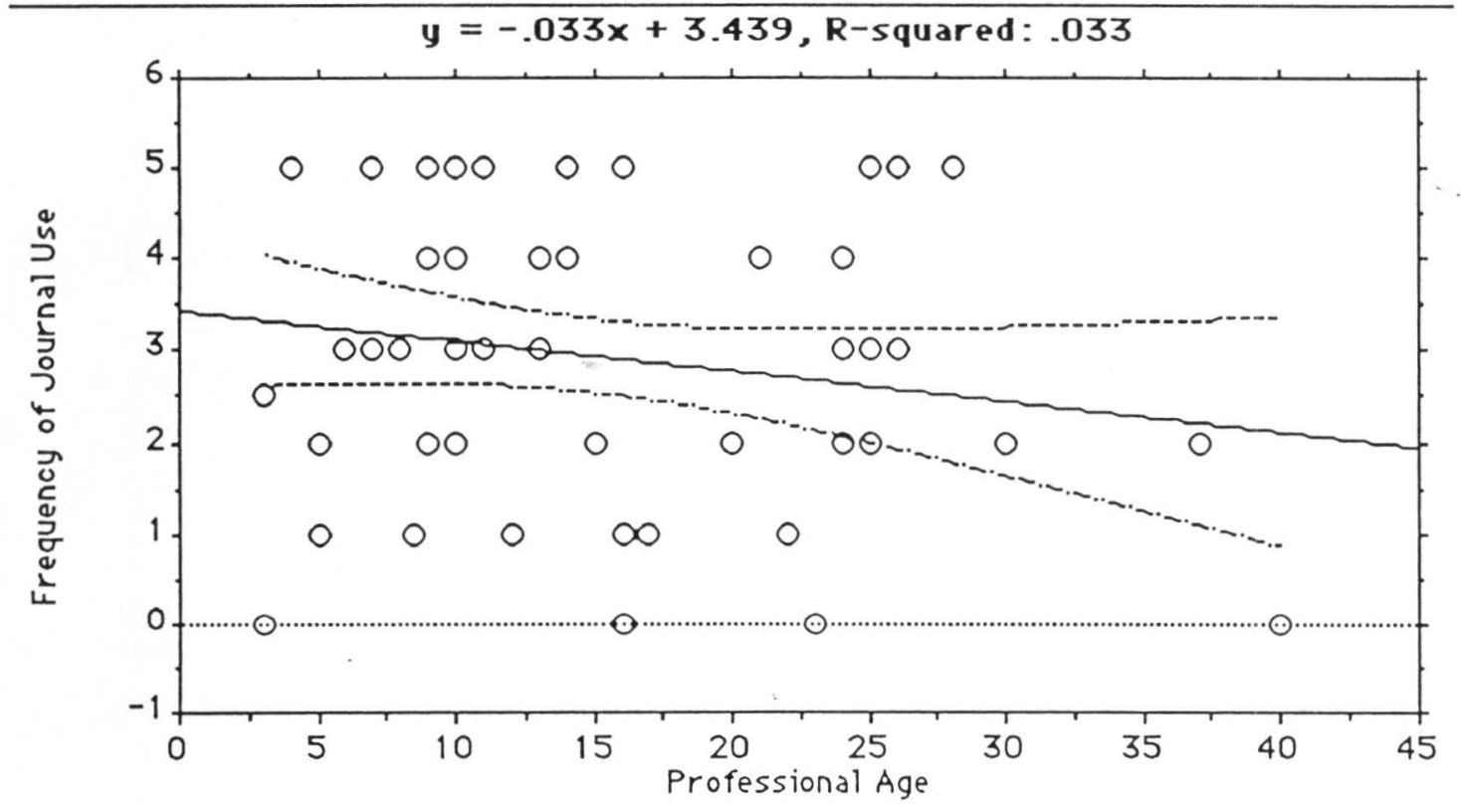


Fig. 17. Relationship Between Professional Age and the Frequency of Book Use

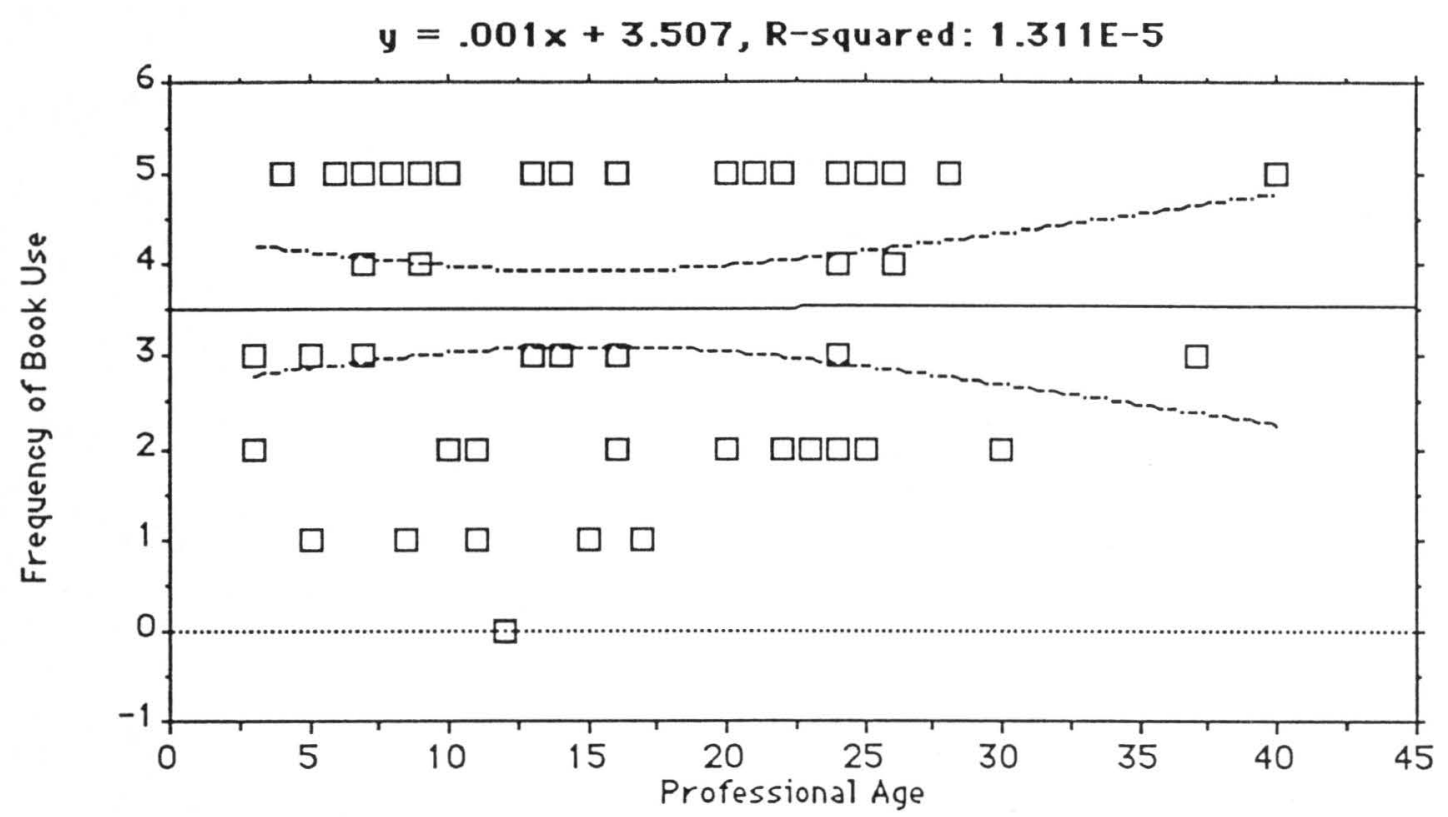

Fig. 18. Relationship Between Professional Age and Print Resource Use

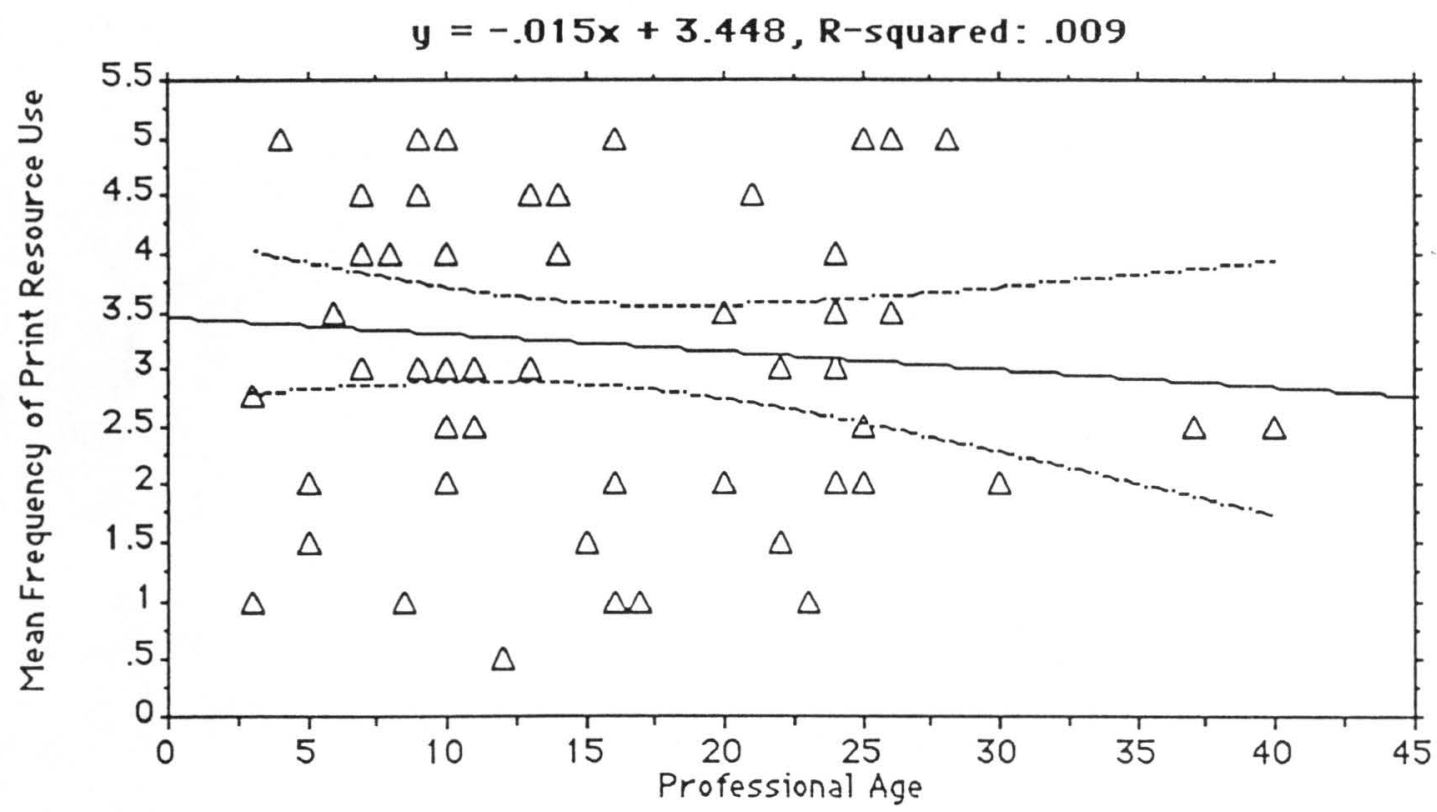


Fig. 19. Table of Regression and Analysis of Variance Values for the Relationship Between the Frequency of Book Use and Professional Age

Simple Regression $X_{1}$ : Professional Age $Y_{2}:$ Frequency of Book Use

\begin{tabular}{|l|l|l|l|l|}
\multicolumn{1}{l}{ R: } & \multicolumn{1}{l}{ R-squared: } & \multicolumn{1}{l}{ Adj. R-squared: Std. Error: } \\
\hline 57 & .004 & $1.311 \mathrm{E}-5$ & -.018 & 1.55 \\
\hline
\end{tabular}

Analysis of Variance Table

\begin{tabular}{l|l|l|l|l|l|} 
Source & DF: & Sum Squares: & Mean Square: & \multicolumn{1}{l}{ F-test: } \\
\hline REGRESSION & 1 & .002 & .002 & .001 \\
\hline RESIDUAL & 56 & 134.481 & 2.401 & $\mathrm{p}=.9785$ \\
\hline TOTAL & 57 & 134.483 & & \\
\hline
\end{tabular}

Fig. 20. Table of Regression and Analysis of Variance Values for the Relationship Between the Frequency of Journal Use and Professional Age

\begin{tabular}{|c|c|c|c|c|}
\hline \multicolumn{3}{|c|}{ Simple Regression $x_{1}$ : Professional Age } & \multicolumn{2}{|c|}{$Y_{1}$ : Frequency of Journal Use } \\
\hline $\mathrm{DF}:$ & $\mathrm{R}:$ & R-squared: & Adj. R-squared: & Std. Error: \\
\hline 57 & .183 & .033 & .016 & 1.538 \\
\hline \multicolumn{5}{|c|}{ Analysis of Variance Table } \\
\hline Source & DF : & Sum Squares: & Mean Square: & F-test: \\
\hline REGRESSION & 1 & 4.573 & 4.573 & 1.933 \\
\hline RESIDUAL & 56 & 132.466 & 2.365 & $p=.1699$ \\
\hline TOTAL & 57 & 137.039 & & \\
\hline
\end{tabular}

Fig. 21. Table of Regression and Analysis of Variance Values for the Relationship Between the Frequency of Print Resources Use and Professional Age

\begin{tabular}{|c|c|c|c|c|}
\hline \multicolumn{5}{|c|}{ Simple Regression $x_{1}$ : Professional Age } \\
\hline DF : & R: & R-squared: & Adj.R-squared: & Std. Error \\
\hline 57 & .096 & .009 & -.008 & 1.348 \\
\hline \multicolumn{5}{|c|}{ Analysis of Variance Table } \\
\hline Source & DF : & Sum Squares & Mean Square: & F-test: \\
\hline REGRESSION & 1 & .957 & .957 & .526 \\
\hline RESIDUAL & 56 & 101.803 & 1.818 & $p=.4712$ \\
\hline TOTAL & 57 & 102.76 & & \\
\hline
\end{tabular}

Ho: There is no difference in the frequency of use of print resources between professionally young chiropractors and professionally older chiropractors.

H1: There is a difference in the frequency of use of print resources between professionally young chiropractors and professionally older chiropractors. 
Figures 16-21 test if there is a linear relationship between professional age and print resources. While the graphs show a slight negative slope, the tables indicate that the relationship is not significant. There is a less than $1 / 20$ chance that there is a linear relationship between print resource use and professional age. Specifically, all the f-values are less than a p-value of 4.0012 (5\% level) which means we fail to reject the null hypothesis that there is no difference in the frequency of use of print resources between professionally young chiropractors and professionally older chiropractors. 


\section{Discussion and Conclusions}

The return rate of $54 \%$ was disappointing in some senses but understandable given the short amount of time the chiropractors had to fill out the survey. However, this rate was better than some user studies in the past (Rasig, Smith et al. 1966; Strasser 1978; Stinson and Mueller 1980; Lovas, Graham et al. 1991). The return rate meant a little over half the population was surveyed and results should be evaluated in light of this. The rate may be an indication of the interest level in library services so some marketing will need to be implemented to raise awareness. Follow-up of non-returnees was not possible due to the short project time period.

While the respondents to the survey were mainly from the younger practitioners, this may not reflect the actual proportions in the whole population. Rather the ages probably represent those interested enough to take part in the survey; younger practitioners could be less apathetic than older practitioners. The spread may also be affected by the retiring of older practitioners.

The large number of chiropractors in city/suburban practice influences the type of conditions they deal with, and therefore the information they may need or want. A study of information needs of both practise types would be useful in this case. Rural practitioners seem to be fewer in number, but are also less likely to have a library containing useful material nearby. Services to this small population can be incorporated into services to chiropractors who live outside Auckland.

Almost all chiropractors in the sample used radiological information as an integral part of their practise. One chiropractor was confused by the question, and worried that there was a hidden implication that chiropractors only used radiological information from journals and not from real patients ${ }^{6}$. The few chiropractors who answered no to this question may have been similarly confused or concerned. It is obvious that radiological information is important to practitioners so the radiological collection should be made available to them in some way. An electronic image database available on-line to NZCA members may be the answer if privacy issues can be resolved.

The high computer use is pleasing in the light of plans by the NZCACC to have a local area network (LAN) and electronic library services to practitioners. The number of practitioners

\footnotetext{
${ }^{6}$ This was prompted by accusations from the medical profession that chiropractors use x-rays taken from journals and books rather than use such information taken from the patient needing treatment. This is in fact untrue. Chiropractors are trained to use radiological equipment and to interpret their own images taken from patients in their care.
} 
with modems could show a willingness to learn new forms of technology and this hopefully will reflect in their future use of electronic services. Some chiropractors commented they used the Internet and it would be interesting to find what kinds of information they used from it, and how efficient they were at finding the information. Use of the Internet could mean the library should have a part on an NZCACC resource page in the future. The few chiropractors with e-mail will provide a core for delivery of information using this fast means of communication.

Hypothesis 4 was not rejected: rural chiropractors do not use electronic information sources any more than urban colleagues. This corroborates (Verhoven, Boerma et al. 1995) findings. The sample of rural chiropractors was small and may have biased the results.

A significant number of practitioners do not use computers at all and therefore are limited to print resources unless they have access to a library with electronic information. Library services will need to take these chiropractors into account (eg. special mail and facsimile services).

Lack of preference for any particular type of information is interesting given that clinical information was the major use of periodical articles by medical practitioners in the study by Lovas, Graham et al., (1991). Chiropractors in the sample seem to want management information just as much as clinical information.

It is also interesting that research articles are considered to be just as useful as other kinds of information as some schools of chiropractic do not promote the scientific research of chiropractic. It is only in the past decade that sustained scientific investigation of chiropractic have been apparent (Coyle and Keating 1992). A service that distributes the contents pages of journals should be feasible in the light of this finding. As mentioned below, the actual use of journal information is low (compared to book use) so this finding backs up initial feelings and comments by those involved in the study that chiropractic information in journals is hard to find and of indifferent quality.

Among the other types of information respondents found useful were seminars but topics for these were not given. Other studies have found such kinds of information sources to be popular also (Strasser 1978; Pelzer and Leysen 1991; Verhoven, Boerma et al. 1995)

The perceived usefulness of the various types of information has implications for collection development in particular. 
Confirming hypothesis 2 and corroborating with other studies (Wood 1971; Strasser 1978) chiropractors use their own personal libraries and their colleagues to get their information. Those sources most often used are those that require little effort on the part of the practitioner; those that require effort such as a library are used little. Conferences were seen to be an important information source by chiropractors; this is borne out by later results. Unlike other studies (Stinson and Mueller 1980), unsolicited material was not as important as other sources.

The low use of libraries corroborates with other user studies (Strasser 1978) and confirms part of hypothesis 1 . This is probably because libraries do not have the kind of information they want. They may also be intimidated by their local library, and/or not taught the importance of libraries while training. the NZCACL will need to market the library as a friendly and useful service to entice their patronage.

Compared to book use, the use of journal information is low but not unreasonably so. The graph for the number of journals read per month is like a normal distribution curve showing that there are those who read many journals to those that read none. Journal use may be low because there are few relevant studies published in the formal literature combined with a lack of knowledge on how to find the information in journals.

In this study, book use seems to be highest (compared to other information sources) among chiropractors unlike other studies (Gomes 1970; Wood 1971; Strasser 1978; Stinson and Mueller 1980; Pelzer and Leysen 1991; Bird and Heekin 1994; Verhoven, Boerma et al. 1995), and this does not support part of hypothesis 1 . The high use may be because the books are already in the chiropractors' possession and therefore are easier to access than journal of electronic information which may require a special effort. The books could be standard texts familiar to the chiropractor. Books are easily accessed in terms of contents whereas journals need to be indexed before they can be searched for contents easily which may be another reason for their high use.

The mean frequency of colleague use as an information source is the same as journal use, and lower than book use. Chiropractors are highly individualistic and there is some rivalry between graduates of different chiropractic schools with their different views on aspects of chiropractic. This is a likely reason for the lower use of colleagues. The geographic isolation of some chiropractors may also limit the amount of colleague use.

The low use of electronic resources is probably due to the lack of useful resources for chiropractors. There are databases available from the United States (as yet not available over 
the Internet) which could be useful if accessible by New Zealand chiropractors. Another reason for the low use (in spite of the high number of chiropractors with computers and modems) is lack of knowledge of the resources available and how to use them. Some respondents commented they would like to use electronic resources more but did not know how.

Those that did use this kind of resource, mainly used the Internet, CD-ROM titles (in particular, management information) and MEDLINE.

From the perceived importance graph (Fig. 14.) it is obvious electronic information is not important to most chiropractors. It will be interesting to see if this changes with the introduction of electronic resources offered by the NZCACL.

Hypothesis 3 was rejected according to the non-significant values produced by the statistical analysis. There seems to be no linear relationship between chiropractors and print information use at all which could indicate chiropractors are unique in this respect. This finding contradicts the studies by Strasser (1978), Stinson and Mueller (1980), Verhoven, Boerma et al. (1995) who found there was a relationship between professional age and print information use. The low numbers of older practitioners may have influenced the results.

The study of chiropractic information use comes at a unique and critical time for the NZCACL and fills a gap in the body of user studies knowledge.

\section{Conclusions}

- The library will need to market its services strongly to the practitioners

- Chiropractors are different to orthodox medical practitioners in that they use monographs more than journals and colleagues, but are similar to medical physician that they rarely use libraries and prefer their own personal collection.

- Electronic information use is low in spite of high computer use and will therefore need special marketing and training to create awareness and use.

- There does not seem to be a need for special recent graduate services as there is no significant linear relationship between professional age and print information use 
- Rural chiropractors and urban chiropractors do not use electronic information any differently, so will probably not need special training or services in this area. They can be accommodated into services as a group.

Word Count: 4836

\section{References}

Bird, G. and J. M. Heekin (1994). "Survey on the use of information sources in the field of ageing." Bulletin of the Medical Library Association 82(1): 30-35.

Bouazza, A. (1988). Information user studies. Encyclopedia of library and Information science. 144-163.

Coyle, B. A. and J. C. Keating (1992). The role and problems of the educational establishment. Toward a philosophy of the science of chiropractic; a primer for clinicians. Stockton, CA, Stockton Foundation for Chiropractic Research. 327-345.

Gomes, S. S. (1970). "The nature of the use and users of the Mid-West Regional Medical Library." Bulletin of the Medical Library Association 58(4): 559-577.

Lin, N. and W. D. Garvey (1972). "Information needs and uses." Annual Review of Information in Science and Technology 7: 5-37.

Lovas, I., E. Graham ... et al. (1991). "Health professionals' use of documents obtained through the Regional Medical Library Network." Bulletin of the Medical Library Association 79(1): 2835 .

Marshall, J. G., D. Fitzgerald... et al. (1993). "A study of library use in problem-based and traditional medical curricula." Bulletin of the Medical Library Association 81(3): 299-305.

Matyn, J. (1974). "Information needs and uses." Annual Review of Information in Science and Technology 9: 2-23.

Pelzer, N. L. and J. M. Leysen (1991). "Use of information resources by veterinary practitioners." Bulletin of the Medical Library Association 79(1): 10-16.

Rasig, L. M., M. Smith ... et al. (1966). "How biomedical investigators use library books." Bulletin of the Medical Library Association 54(2): 104-7.

Stinson, E. R. and D. Mueller (1980). "Survey of health professionals' information habits and needs: conducted through personal interviews." Iournal of the American Medical Association 243(2): 140-143.

Strasser, T. C. (1978). "The information needs of practising physicians in North Eastern New York State." Bulletin of the Medical Library Association 66(2): 200-209. 
Verhoven, A. A. H., E. J. Boerma ... et al. (1995). "Use of information sources by family physicians: a literature survey." Bulletin of the Medical Library Association 83(1): 85-90.

Wood, D. N. (1971). "User studies: a review of the literature from 1966 to 1970." ASLIB Proceedings 23(1): 11-23. 
Appendix A 


\section{Dear Chiropractor,}

My name is Penny Dawson, and I am your librarian at the Centennial Library N.Z.C.A. Centre. I have prepared this survey as part of the requirements needed to upgrade my Diploma of Library and Information Studies to a Masters qualification. My study is to find out how chiropractors use information. I am hoping to be able to offer some information services to chiropractors in the Association so the results of this survey will help me to get to know your information habits and the kind of library services that would be most useful to you.

The survey is totally anonymous complying with the guidelines of the Human Ethics Committee at Victoria University of Wellington. I would be extremely grateful if you could take the time to fill in the survey and return it promptly. I am anxious to get at least a $75 \%$ return rate else my results will not be valid.

Please return the completed survey in the self addressed envelope provided, or fax it to the N.Z.C.A. Centre (09 373 5973). Surveys should be returned by the 5th of February so I am able to complete the project and meet the deadlines set by Victoria University of Wellington.

If you would like to see the results, or contact me about this survey, I am available:

- at the N.Z.C.A. Centre Ph: 093734343 Fax. 093735973 (Mon. - Thurs.)

- at home 096279497 (evenings)

- by e-mail Penelope.Dawson@vuw.ac.nz

1. How long have you been practising?

2. Which category does your practice fit into? (Tick one)

in the city or its suburbs?

in a predominantly rural area?

$\square$ other? (Please specify)

3. Do you use radiological information in your practice? (Tick one)

Yes

No 
4. Do you own or have access to a computer that you use regularly? (Tick one)

$\square$

No

Yes

$\Rightarrow$ Do you have a modem? No $\square$ Yes $\square$

$\Rightarrow$ Do you have email? Yes $\square$ No $\square$

$\Rightarrow$ Do you have access to the Internet? Yes $\square$ No $\square$

For the purposes of this survey the definition of information use is as follows:

Information use is a seeking behaviour that leads to collection of information sources (eg. journals) for the sake of their contents which are put to sorne purpose or availed upon such that further behaviours result.

5. What kinds of information help you in your practise and understauciung of chiropractic? (Tick as many as appropriate)

Advice on techniques

Management of practice

Research articles

Case management

Case studies

Other(s) (Please specify) 
6. Where does this information come from at present? (Tick as many as appropriate)

journals

1 colleagues

books

conferences

electronic databases

Other(s) (Please specify)

7. Where do you get these information sources from? (Tick as many as appropriate)

1. Personal libraries or subscriptions

2. Colleagues

3. Unsolicited material given to you

4. A hospital or medical library

5. A database that you own

6. A database you access remotely

7. The Internet

8. Other(s)

(Please specify):

8. Which of the sources in question seven is the main source of your information? (Circle one number)

$\begin{array}{llllllll}1 & 2 & 3 & 4 & 5 & 6 & 7 & 8\end{array}$


9. Approximately how often do you use a library to get information for use in your practice? (Tick one)

more than once a week

once a week

once a fortnight

once a month

1-6 times a year

never

10. How many journals relevant to your practise do you read each month? (These do not have to be specific chiropractic journals. For example, if you read management or computer magazines and they help you run a better practice then please include them). (Circle one number)

$\begin{array}{llllll}0 & 1 & 2 & 3 & 4 & 5 \text { or more }\end{array}$

11. Approximately how often do you consult these journals for information relevant to your practice? (Tick one)

more than once a week

once a week

once a fortnight

once a month

1-6 times a year

not at all

12. What are the titles of these journals? 
13. Approximately how often do you consult books to use in your practice? (Tick one)

more than once a week

$\square$ once a week

$\square$ once a fortnight

$\square$ once a month

$\square$ 1-6 times a year

$\square$ not at all

14. Approximately how often do you consult colleagues for information to use in your practise? (Tick one)

$\square$ more than once a week

$\square$ once a week

once a fortnight

$\square$ once a month

1-6 times a year

$\square$ not at all

15. Approximately how often do you use electronic sources of information to use in your practice? (Tick one)

$\square$ more than once a week

$\square$ once a week

once a fortnight

$\square$ once a month

1-6 times a year

$\square$ not at all

If you use electronic sources at all please answer the following questions:

Please write down what kind of electronic resource you use. 
$\Rightarrow$ Do you access these remotely (ie. using a modem)? Yes $\square$ No $\square$

are they your own / on your hard drive / on a floppy disc /

on CD-ROM? Yes $\square$ No $\square$

do you go to a particular place to use them? Yes $\square$ No $\square$

$\Rightarrow$ Where?

16. How important are the following sources to you? (Circle one number)

Not important

Very important

\begin{tabular}{llllll} 
Journals & 1 & 2 & 3 & 4 & 5 \\
Colleagues & 1 & 2 & 3 & 4 & 5 \\
Books & 1 & 2 & 3 & 4 & 5 \\
$\begin{array}{l}\text { Electronic } \\
\text { databases }\end{array}$ & 1 & 2 & 3 & 4 & 5 \\
Conferences & 1 & 2 & 3 & 4 & 5 \\
Others (Please specify) & & & & \\
\hline & 1 & 2 & 3 & 4 & 5 \\
\hline & 1 & 2 & 3 & 4 & 5 \\
\hline & 1 & 2 & 3 & 4 & 5 \\
\hline
\end{tabular}

Thank you for taking the time to fill out this survey. Please return it in the self addressed envelope or fax it to the N.Z.C.A. centre by the 5th of February 1996.

I would like to gather a group of interested chiropractors together in order to discuss possible services the library could/should offer to practitioners in the future. I will have certain questions to ask, (eg. the kind of access practitioners would like to have). but the forum is open for other questions and concerns to be raised. The results of this discussion would be beneficial to all practitioners, and has the potential to be interesting and fun. I anticipate the discussion to take no longer than $11 / 2-2$ hours depending on the number and dynamics of those present. It will likely be held at the N.Z.C.A. Centre at a time convenient for as many as possible. Unfortunately I have no grant to support my research, so while I am happy to provide refreshments, travel and time costs will have to be met by those interested.

If you are interested in being part of this, please fill in the slip below and mail or fax it to 
Appendix B 
Dear Chiropractor,

As some may already know, my name is Penny Dawson, and I am your librarian at the Centennial Library N.Z.C.A. Centre. While working here at the Centennial Library I am in the process of upgrading my librarian's qualification to a Masters degree, and this survey is part of the research component of the upgrade. My study is to find out how chiropractors use information.

I am hoping to be able to offer some information services to chiropractors in the Association so the results of this survey will help me to get to know your information habits and the kind of library services that would be most useful to you.

The survey is anonymous. I would be extremely grateful if you could take the time to fill in the survey and return it promptly. I am anxious to get at least a $75 \%$ return rate else my results will not be valid.

Please return the completed survey in the self addressed envelope provided, or fax it to the N.Z.C.A. Centre (09 373 5973). Surveys should be returned by the 5 th of February so I am able to complete the project and meet the deadlines set by Victoria University of Wellington.

If you would like to contact me regarding this survey, I am available:

- at the N.Z.C.A. Centre Ph: 093734343 Fax. 093735973 (Mon. - Thurs.)

- at home 096279497 (evenings)

- by e-mail Penelope.Dawson@vuw.ac.nz

1. How many years have you been practising?

2. Is your practice (Tick one)

in the city or its suburbs?

in a predominantly rural area?

other?

(Please specify)

3. Do you use $x$-rays or other images, or radiological information from sources such as journals as an integral part of your treatment? (Tick one)

Yes

No 
4. Do you own or have access to a computer that you use regularly? (Tick one)

No

Yes

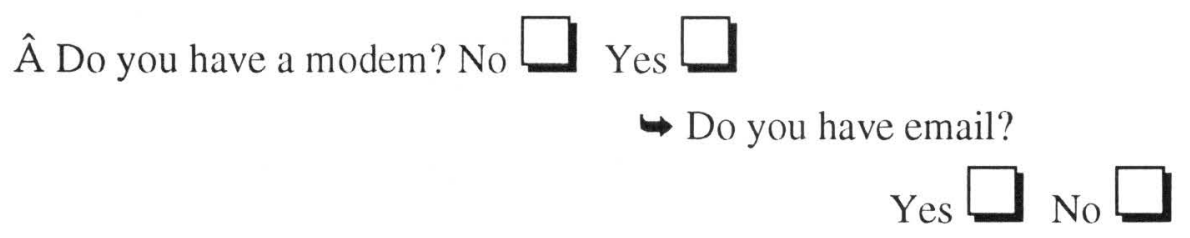

Â Do you have access to the Internet? Yes $\square$ No $\square$

For the purposes of this survey the definition of information use is as follows:

Information use is a seeking behaviour that leads to collection of information sources (eg. journals) for the sake of their contents which are put to some purpose or availed upon such that further behaviours result.

5. What kinds of information helps you in your practice and understanding of chiropractic? (Tick as many as appropriate)

Advice on techniques

Management of practice

Research articles

Case Management

Case Studies

Other(s) (Please specify) 
6. Where do you get information from at present? (Tick as many as appropriate)

1. Personal libraries or subscriptions (or print material lent to you by colleagues)

2. Colleagues (informal verbal communication as opposed to sharing books and journals)

3. Unsolicited material given to you

4. A hospital or medical library

5. A database that you own

6. A database you access remotely

7. The Internet

8.Trade representatives

9. Conferences

10. Other(s)

(Please specify):

7. Approximately how often do you use a library to get information for use in your practice? (Tick one)

more than once a week

once a week

once a fortnight

once a month

1-6 times a year

never

8. If you do use a library to get information for use in your practice, is it: (Tick one)

a public library?

a medical library?

another kind of library? 
9. How many journals relevant to your practise do you read each month? (These do not have to be specific chiropractic journals. For example, if you read management or computer magazines and they help you run a better practice then please include them) (Circle one number)

$\begin{array}{llllll}0 & 1 & 2 & 3 & 4 & 5 \text { or more }\end{array}$

10. Approximately how often do you consult these journals for information relevant to your practice? (Tick one)

more than once a week

once a week

once a fortnight

once a month

1-6 times a year

not at all

11. What are the titles of these journals? 
12. Approximately how often consult books to use in your practice? (Tick one)

more than once a week

once a week

once a fortnight

once a month

$1-6$ times a year

not at all

13. Approximately how often do you consult colleagues for information to use in your practise? (Tick one)

more than once a week

once a week

once a fortnight

once a month

1-6 times a year

not at all

14. Approximately how often do you use electronic sources of information to use in your practise? (Tick one)

more than once a week

once a week

once a fortnight

once a month

1-6 times a year

not at all

$\rightarrow$ If you use electronic sources at all please answer the following two questions:

Please write down what kind of electronic resource you use. 
$\Rightarrow$ Do you access these remotely (ie. using a modem)? $\square$

or are they your own/ on your hard drive/ on a floppy disc / on CD-ROM?

or do you go to a particular place to use them?

Where?

15. How important are the following sources to you? (Circle one number for each source) Not important

Very important

$\begin{array}{llllll}\text { Journals } & 1 & 2 & 3 & 4 & 5 \\ \text { Colleagues } & 1 & 2 & 3 & 4 & 5 \\ \text { Books } & 1 & 2 & 3 & 4 & 5\end{array}$

Electronic

$\begin{array}{cccccc}\text { databases } & 1 & 2 & 3 & 4 & 5 \\ \text { Conferences } & 1 & 2 & 3 & 4 & 5\end{array}$

Others

$\begin{array}{llllll}1 & 2 & 3 & 4 & 5 \\ & 1 & 2 & 3 & 4 & 5 \\ 1 & 2 & 3 & 4 & 5 \\ 1 & 2 & 3 & 4 & 5\end{array}$

Thank you for taking the time to fill out this survey. Please return it in the self addressed envelope or fax it to the N.Z.C.A. centre by the 5th of February 1996.

I would like to gather a group of interested chiropractors together in order to discuss possible services the library could/should offer to practitioners in the future. I will have certain questions to ask, (eg. the kind of access practitioners would like to have), but the forum is open for other questions and concerns to be raised. The results of this discussion would be beneficial to all practitioners, and has the potential to be interesting and fun. I anticipate the discussion to take no longer than $1 \frac{1}{2}-2$ hours depending on the numbers and dynamics of those present. It will likely be held at the N.Z.C.A. Centre at a time convenient for as many as possible. Unfortunately I have no grant to support my research, so while I am happy to provide refreshments, travel and time costs will have to be met by those interested.

If you are interested in being part of this, please fill in the slip below and mail or fax it to 
me at:

457 Hillsborough Rd

Auckland 4

Ph. (09) 6279497

or:

Penny Dawson

P O Box 7144

Wellesley St

Auckland 1036

Ph: (09) 3734343

Fax: (09) 3735973

It is important you mail/fax this separately from the questionnaire to maintain the anonymity the Victoria University Human Ethics Committee requires.<smiles>SCCS</smiles>

Yes I am interested in taking part in the group discussion about possible library services to practitioners to be held at the N.Z.C.A. Centre.

My name, address and contact phone number are as follows:

The best times for me would be:

mornings

afternoon

evenings

anytime

The best day of the week for me would be:

Monday Tuesday Wednesday Thursday Friday Saturday

Any day of the week 


\title{
Victoria University of Wellington \\ Department of Library \& Information Studies
}

Master of Library \& Information Studies

IMPORTANT DISCLAIMER

with respect to a MLIS Research Project (LIBR 550)

(hereafter referred to as 'The MLIS Research Project')

\author{
being undertaken by \\ Penelope Jane Dawson \\ in partial fulfilment of the requirements of the \\ Master of Library \& Information Studies, \\ Department of Library \& Information Studies, Victoria University of Wellington.
}

Topic Commencement:

1. Victoria University of Wellington and its Council, its members, staff, employees, students and agents undertake no duty of care in contract, tort, or otherwise, to users (whether direct or indirect) of the MLIS Research Project and make no warranties or representations of any kind whatsoever in relation to any of its contents.

2. The MLIS Research Project is only made available on the basis that all users of it, whether direct or indirect, must take appropriate legal or other expert advice in relation to their own circumstances and must rely solely on their own judgement and such legal or other expert advice.

3. Under no circumstances will Victoria University of Wellington and its Council, its members, staff, employees, students or agents be liable in any way whatsoever, whether in contract, tort (including negligence), for breach of any statutory or regulatory duty (to the fullest extent permissible by law), or otherwise, to any user (whether direct or indirect) of the MLIS Research Project for any loss or damage whatsoever arising directly or indirectly as a result of the use in any way of the MLIS Research Project.

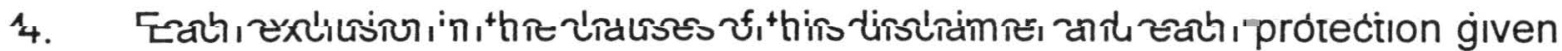
by it is to be construed as a separate exclusion applying and surviving even if for any reason any of the exclusions or protections are held inapplicable in any circumstance. 